\title{
Myringoplasty Modification Adopted to Overcome Some Long and Short Term Surgical Issues
}

\author{
Raja Salman Khurshid, Nisar Hussain Madni \\ MMABM Hospital, Anantnag, India \\ Email: salmanwanidr@gmail.com
}

How to cite this paper: Khurshid, R.S. and Madni, N.H. (2019) Myringoplasty Modification Adopted to Overcome Some Long and Short Term Surgical Issues. International Journal of Otolaryngology and Head \& Neck Surgery, 8, 71-79.

https://doi.org/10.4236/ijohns.2019.82008

Received: January 7, 2019

Accepted: March 1, 2019

Published: March 4, 2019

Copyright $\odot 2019$ by author(s) and Scientific Research Publishing Inc. This work is licensed under the Creative Commons Attribution International License (CC BY 4.0).

http://creativecommons.org/licenses/by/4.0/

\begin{abstract}
Objective/Hypothesis: We have tried to present some of our concerns regarding the usually adopted surgical techniques of Myringoplasty with their possible solutions. Also we have tried to present digital recordings of pre and post-operative findings in reference cases, which have been provided rarely in available literature. Pre- and post-operative pictures and videos of two representative cases are attached. Study design: This prospective study was carried out in MMABM hospital. Forty six (46) ears, 37 patients underwent tympanoplasty by the modified dual grafting technique and the results were analysed. Results: Objectives of tympanic membrane repair, dry ear, closure of $\mathrm{AB}$ gap, and stoppage of tinnitus if any, were achieved in all cases. Small residual perforations which healed over time were seen in two cases in cartilage deficient areas. Conclusion: Dual graft modified techniques served as an effective alternative myringoplasty technique.
\end{abstract}

\section{Keywords}

Myringoplasty Modifications, Cartilage Tympanoplasty, Dual Grafting Myringoplasty

\section{Introduction}

Myringoplasty techniques have already reached a pinnacle with all the described techniques producing excellent results [1] [2] [3]. Stillit is one of those surgical procedures where no one follows a routine course. All the surgeons we have seen operating use their own modifications and techniques which better suit them. And also surgeons keep on modifying and varying their techniques with each case. Taking heart from this we have tried to present some of our concerns re- 
garding the usually adopted surgical techniques of Myringoplasty with their possible solutions. Also we have tried to present digital recordings of pre and post-operative findings in reference cases, which have been provided rarely in available literature. Pre and post operative pictures of two representative cases are shown.

\section{Surgical issues of concern:}

1) Neo-tympanum may be thin/transparent/weak vulnerable to trauma (barotrauma mostly) or may perforate easily in case of any re-infection [2] [3].

2) Neo-tympanum may be thin/weak vulnerable to form retraction pockets which in long term may lead to atelectasis or cholesteatoma formation [3].

3) Re-perforation/retraction/cholesteatoma formation because of any reason leads to loss of faith and trust in surgeons and the surgical procedure itself, despite all the efforts of explaining the pathogenesis, especially in a closed setup and rural communities [4].

4) Placement of graft in the usual surgical techniques does not give much leverage to the surgeon as graft needs to be properly supported with an assured tucking in under the tympanic membrane annulus.

\section{Modification:}

Instead of one, we have used two grafts in this technique. The temporalis fascia graft is harvested as usual. Then a tragal cartilage $1 \mathrm{~cm} \times 1 \mathrm{~cm}$ piece with perichondrium at least on one side intact is harvested. The bulkier ends of the cartilage are trimmed with a surgical blade. The cartilage could be made as trim as needed. Then the cartilage is placed to fill in the perforation. The cartilage is placed below the level of neck of the malleus taking care not to block the aeration/ventilation channels of middle ear which are all known to exist above this level. Again care is taken that the cartilage size should not be more than the actual size of perforation, and it just fits in the perforation. If the cartilage does not fit in, it is divided into multiples pieces to cover the area of the perforation. Then the temporalis fascia graft is placed and tucked under the tympanic membrane remnant as usual followed by gel foam packing of EAC. Size of the perforation guides about the size of cartilage to be used. However, we have not favoured any particular size of perforation for using the cartilage graft.

\section{Efforts to overcome the concern:}

1) Placement of cartilage with or without temporalis facia graft gives a stiffness and strength to the neo-tympanum which may not perforate that easily in case of any trauma (like barotrauma).

2) Strong and stout neo-tympanum is more likely to be resistant to from retraction pockets, thus decreasing the chances of atelectasis post operatively or even cholesteatoma formation.

3) Theoretically placement of the cartilage graft along-with the perichondrium overcomes the concerns of placing a graft which may or may not survive for long due to doubtful nutritional support.

4) Placement of temporalis fascia graft in a case where a cartilage support is provided becomes much easier, and intra-operatively the graft tucks to tympanic 
membrane closely and provides a lot of margin to the surgeon.

5) The healing time and neo-tympanum formation time may change with theoretical prospect of quicker and more assured healing when stouter cartilage graft with perichondrium is used.

Concerns regarding the modified technique:

1) Thick and stout neo-tympanum decreases the chances of air-bone gap closure.

2) The ventilation channels of middle ear may get blocked with the cartilage pieces resulting in post-operative retraction pockets.

3) Prolongation of operating time as two grafts needs to be harvested.

4) An opaque neo-tympanum may be of concern in the follow-up of these patients.

\section{Commentary on concerns:}

Use of cartilage makes the neo-tympanum opaque and stout. Despite a theoretical concern of affecting the air bone gap closure chances, it has been seen that the effect on $A B$ gap is statistically insignificant, or that the patients are unaware of any conductive deafness [5] [6]. Use of cartilage slicer to thin out the bulkier portions of the graft may further obtund these concerns. However, in this study cartilage slicer has not been used.

Care is taken to place the cartilage pieces below the level of ossicles preferably below the level of neck of malleus. This theoretically reduces the chances of block of ventilation channels and reduces the incidence of post-operative retraction pockets. This is supported by the fact that the ventilation channels in middle ear lie in the epitympanum or at the level of junction of mesotympanum and epitympanum [7].

As the placement of graft takes much less time when the cartilage is already in place, the overall operating time is not significantly affected.

Use of such a technique further strengthens the belief that tympanoplasty/myringoplasty is a high output surgical procedure with a universal success rate and excellent surgical outcome despite any modifications adopted.

\section{Material \& Methods}

This study was carried out in MMABM hospital. Forty six (46) ears, 37 patients underwent tympanoplasty by the modified dual grafting technique. Patients in the teens, third and fourth decades were included. All the patients included had CSOM of inactive mucosal type with a safe disease and with perforations of all sizes. This ensured that most of the cases could be done under local anaesthesia and uniformity of the procedure could be expected. Only 03 patients were of age less than 15 yrs and had to be operated under general anaesthesia. Also all the cases were operated by one surgeon for uniformity. Cholesteatoma or patients with unsafe CSOM type where not included in this series. The results were analysed and compared with the cases done previously in the same hospital using the conventional single graft technique. The results were also analysed for com- 
parison with the published data in various journals that could be retrieved by PubMed/Medline search. The features that were compared pre and post operatively included perforation closure rates, pure tone audiograms, and patient satisfaction score.

\section{Results/Observations}

1) Age of the patients ranged from 11 to 48 . Most of the patients of this age group were selected to allow for patient cooperation and cases to be done under local anaesthesia. Only 3 cases who were less than 15 years were operated under general anaesthesia.

2) Out of the 37 patients operated, 26 were females and 11 were males. In 9 patients both ears were operated. This is depicted in Table 1 below.

All these patients belonged to rural areas or to small towns, and had long standing chronic otitis media with stable perforations on examination. This is mentioned in Table 2 below.

3) All the patients had inactive mucosal CSOM with central or subtotal perforation. Patients with attic perforations, mastoid involvement, or cholesteatoma were dealt with separately and were not part of this study. Most of the ears had subtotal to total perforation, and the rest had central perforations of various sizes.

4) Preoperative audiograms revealed conductive deafness ranging from $24 \mathrm{db}$ to $51 \mathrm{db}$. Preoperative CT scans had been ordered in two patients only, revealing no mastoid cell coalescence. All other patients had a preoperative mastoid radiograph done to rule out any coalescence.

5) Ossicular erosions were seen in four (04) ears preoperatively and were managed with incus repositioning in 3 cases and PORP prosthesis in one case.

6) Postoperative complications: Postoperative recovery was uneventful in all except in one patient who got injury (slap) on $12^{\text {th }}$ postop day and had a ruptured TM. But fortunately it healed in 2 weeks' time and he recovered completely. In the postoperative period, 7 patients complained of headache with normal ENT examination. All these patients were managed as primary headaches and responded well to low dose Nortriptyline.

7) The perforation closure assessed at 3 weeks revealed small residual perforations in two cases in anteroinferior and anterosuperior quadrants respectively.

Table 1. Distribution of patients.

\begin{tabular}{cccc}
\hline Number of ear operated & Number of patients & Males & Females \\
\hline 46 & 37 & 11 & 26 \\
\hline
\end{tabular}

Table 2. Classification of perforations on preoperative examination.

\begin{tabular}{cccc}
\hline $\begin{array}{c}\text { Number of } \\
\text { ears operated }\end{array}$ & $\begin{array}{c}\text { Total perforation } \\
\text { preoperatively }\end{array}$ & $\begin{array}{c}\text { Subtotal perforation } \\
\text { preoperatively }\end{array}$ & $\begin{array}{c}\text { Central perforations } \\
\text { of various sizes }\end{array}$ \\
\hline 46 & 23 & 12 & 11
\end{tabular}


The perforation sites coincided with the cartilage deficient sites in these cases. These perforations healed completely after 3 months in one case and at 6 months in another. Thus, we had a perforation closure rate of $100 \%$ in these cases.

8) Pre- (Figure $1 \&$ Figure 2) and post-operative (Figure 3 \& Figure 4) pictures are shown in two representative cases.

9) Postoperative audiograms revealed reduction of air-bone gap to 12 to $25 \mathrm{db}$ with all the patients unaware of any conductive deafness.

Figure 5 and Figure 6 compare the preoperative audiogram with postoperative status in a representative case operated employing modified dual graft technique.

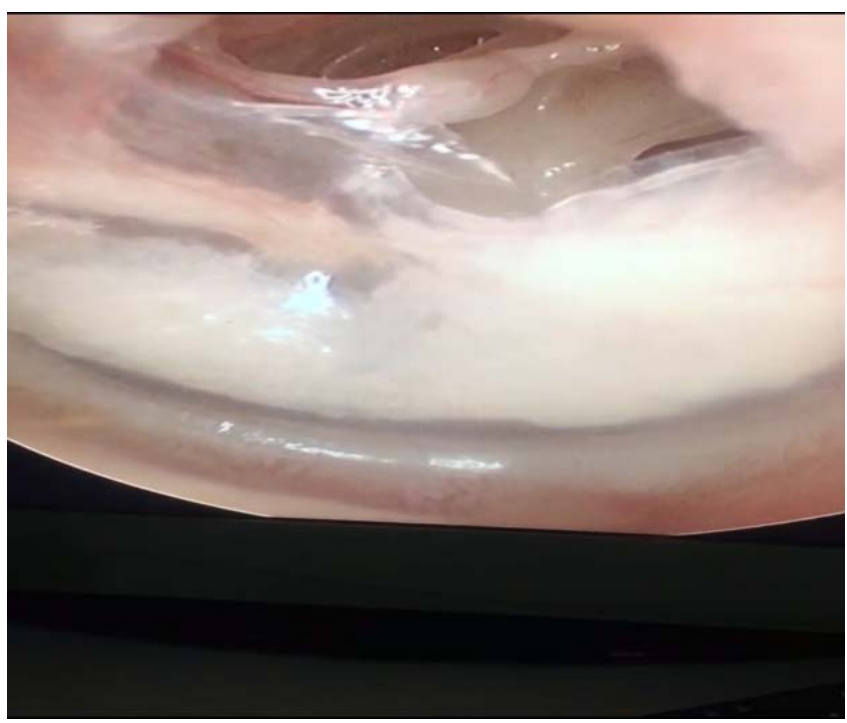

Figure 1. Case 1: Pre-operative.

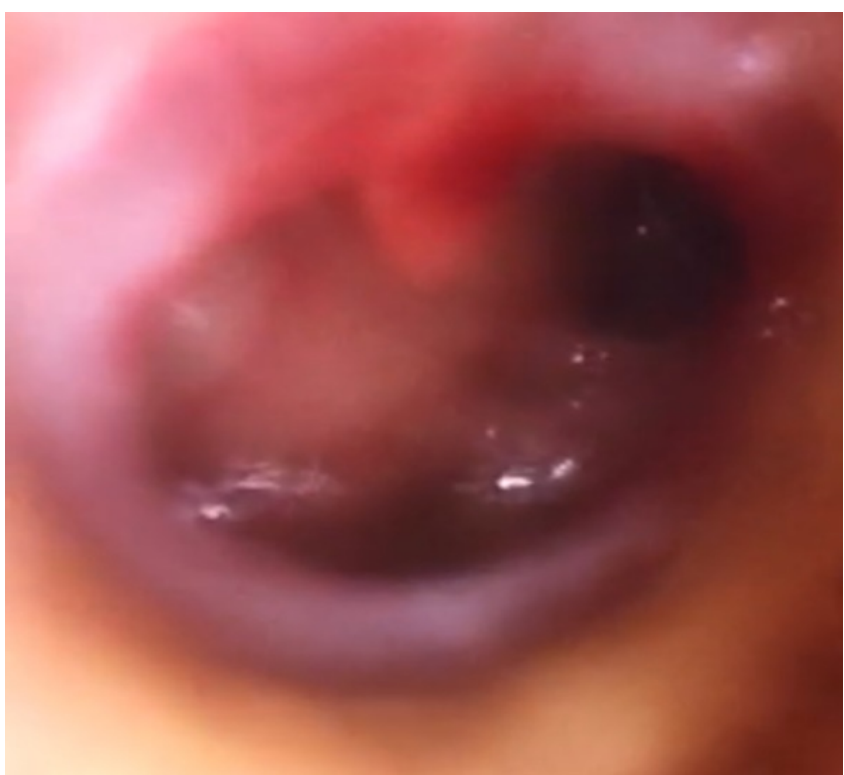

Figure 2. Case 2: Pre-operative. 


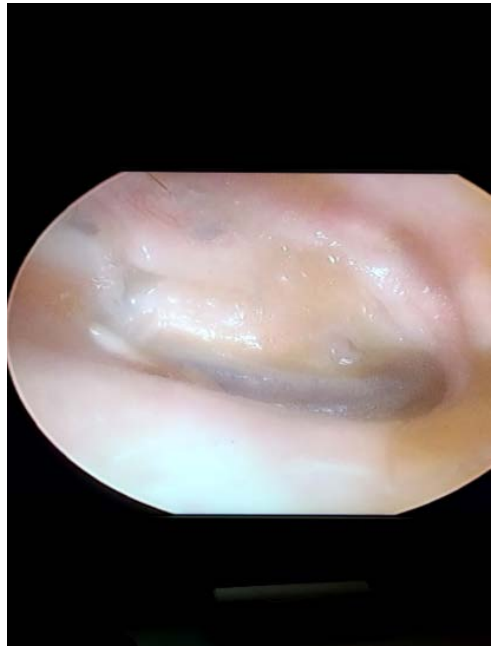

Figure 3. Case 1: Post-operative.

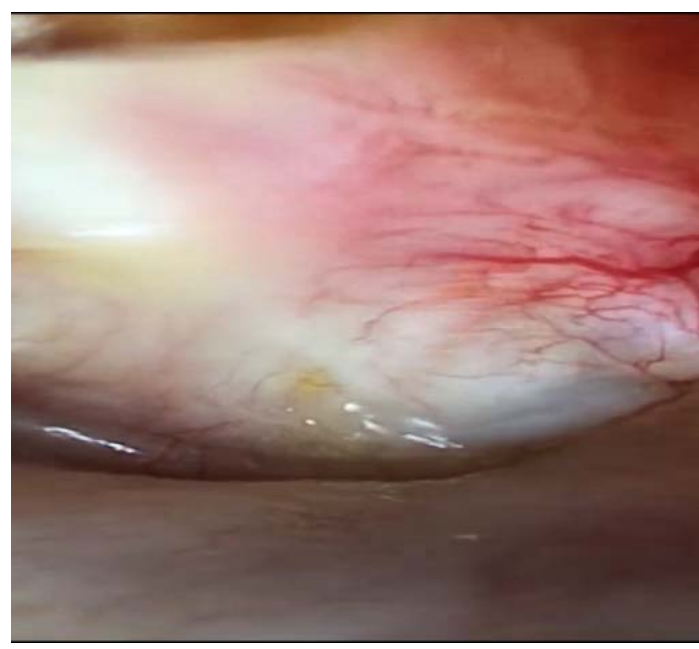

Figure 4. Case 2: Post-operative.

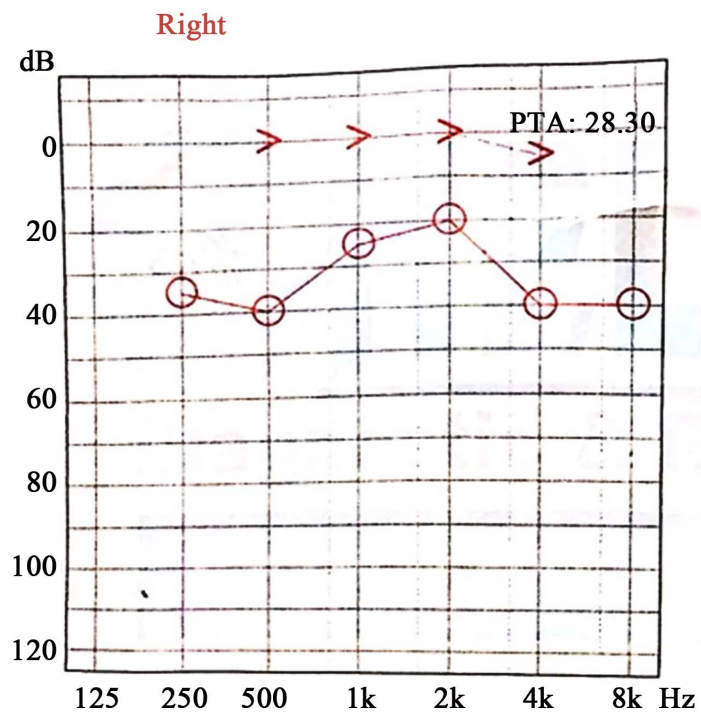

Figure 5. Preoperative audiogram in reference case. 


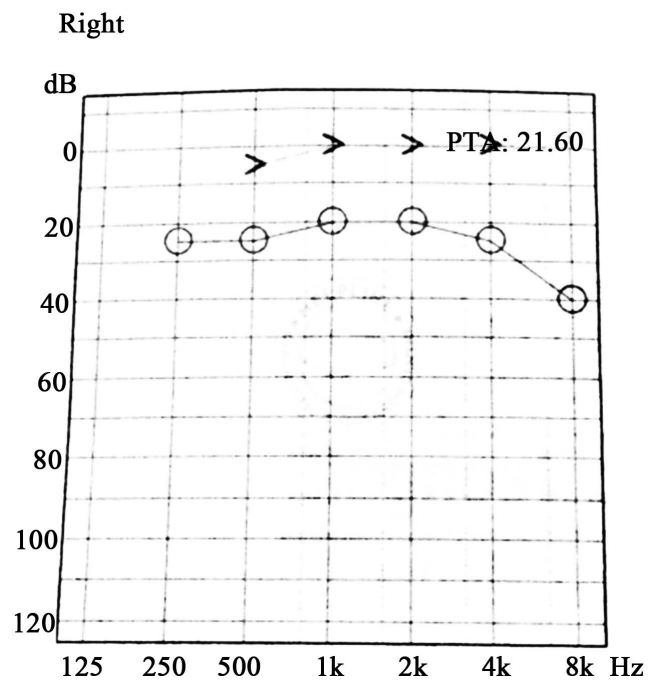

Figure 6. Postoperative audiogram in the same case.

\section{Discussion}

The use of cartilage for tympanic membrane repair is extensively reported in literature [8] [9] and the benefits of long-term graft survival, low recurrence and infection rates have been described, particularly decreased development of tympanic membrane retraction pockets over time [10] [11]. Most of the authors have reported excellent functional results for small and large perforations [12] [13]. Cartilage tympanoplasty comprises a heterogeneous group of techniques including the cartilage-perichondrium composite graft, diced cartilage, butterfly techniques, and palisade cartilage tympanoplasty [14]. Tos M. reviewed 23 different cartilage tympanoplasty methods and grouped them into six categories from A to F [15]. The method adopted by us in this report could be classified a modified category F cartriage tympanoplasty described by Tos.

The modified dual graft myringoplasty provides all the benefits that cartilage tympanoplasty is known for (like decreased chances of retraction pockets and higher rates of perforation closure), besides the added intra-operative manoeuvrability benefits for the surgeon. The graft placement and tucking is much easier with this technique. This advantage may be utilised positively by younger ear surgeons in the earlier periods of training. The maintenance of middle ear space does not seem to be an issue since the ventilation channels of middle ear space are maintained by ensuring that the cartilage graft is placed in the lower mesotympanum.

All the objectives of tympanoplasty, namely dry ear, well-formed and stout tympanic membrane, free of retraction pockets, reversal of conductive deafness, and with the result full confidence in the procedure are achieved with this technique. However, as long as this technique is not replicated by other surgeons the apprehensions over the possible persistent conductive deafness and failure to heal will remain. This report is an attempt to convince the fellow ear surgeons about the multitude of possible techniques that can be adopted with confidence, 
particularly in view of the digital recordings as a proof.

\section{Conclusion}

The repair of tympanic membrane, being one of the commonest ENT procedures, has varied techniques with the basic principles unaltered in each. The procedure adopted can be modified with enough confidence by individual depending on what works best for each.

\section{Conflicts of Interest}

The authors declare no conflicts of interest regarding the publication of this paper.

\section{References}

[1] Kalsotra, P., Gupta, R., Gupta, N., Kotwal, S., Suri, A. and Kanotra, S. (2014) Overlay versus Underlay Myringoplasty: A Comparative Study. Indian Journal of Otology, 20, 183-188. https://doi.org/10.4103/0971-7749.146935

[2] Sergi, B., Galli, J., De Corso, E., Parrilla, C. and Paludetti, G. (2011) Overlay versus Underlay Myringoplasty: Report of Outcomes Considering Closure of Perforation and Hearing Function. ACTA Otorhinolaryngologica Italica, 31, 366-371.

[3] Buckingham, R.A. (1992) Fascia and Perichondrium Atrophy in Tympanoplasty and Recurrent Middle Ear Atelectasis. Annals of Otology, Rhinology \& Laryngology, 101, 755-758. https://doi.org/10.1177/000348949210100907

[4] Jesic, S.D., Dimitrijevic, M.V., Nesic, V.S., Jotic, A.D. and Slijepcevic, N.A. (2011) Temporalis Fascia Graft Perforation and Retraction after Tympanoplasty for Chronic Tubotympanic Otitis and Attic Retraction Pockets: Factors Associated with Recurrence. Archives of Otolaryngology-Head and Neck Surgery, 137, 139-143. https://doi.org/10.1001/archoto.2010.242

[5] Vashishth, A., Mathur, M.N., Choudhary, S.R. and Bhardwaj, A. (2014) Clinical Advantages of Cartilage Palisades over Temporalis Fascia in Type I Tympanoplasty. Auris Nasus Larynx, 41, 422-427. https://doi.org/10.1016/j.anl.2014.05.015

[6] Chabra, G., Saxena, A.K. and Kumar, S. (2018) Comparative Study of Temporalis Fascia Graft versus Cartilage Shield Tympanoplasty. International Journal of Otorhinolaryngology and Head and Neck Surgery, 4, 951-955. https://doi.org/10.18203/issn.2454-5929.ijohns20182019

[7] Maniu, A., Catana, I.V., Harabagiu, O., Petri, M. and Cosgarea, M. (2013) Anatomical Variants of Tympanic Compartments and Their Aeration Pathways Involved in the Pathogenesis of Middle Ear Inflammatory Disease. Clujul Medical, 86, 352-356.

[8] Dornhoffer, J. (2003) Cartilage Tympanoplasty: Indications, Techniques, and Outcomes in a 1,000-Patient Series. Laryngoscope, 113, 1844-1856. https://doi.org/10.1097/00005537-200311000-00002

[9] Dornhoffer, J.L. (2006) Cartilage Tympanoplasty. Otolaryngologic Clinics of North America, 39, 1161-1176. https://doi.org/10.1016/j.otc.2006.08.006

[10] Cabra, J. and Monux, A. (2010) Efficacy of Cartilage Palisade Tympanoplasty: Randomized Controlled Trial. Otology \& Neurotology, 31, 589-595. https://doi.org/10.1097/MAO.0b013e3181dbb35e

[11] Velepic, M., Bonifacic, M. and Manestar, D. (2001) Cartilage Palisade Tympanoplasty and Diving. Otology \& Neurotology, 22, 430-432. 
https://doi.org/10.1097/00129492-200107000-00002

[12] Gerber, M.J., Mason, J.C. and Lambert, P.R. (2000) Hearing Results after Primary Cartilage Tympanoplasty. Laryngoscope, 110, 1994-1999.

https://doi.org/10.1097/00005537-200012000-00002

[13] Neumann, A. and Jahnke, K. (2005) Reconstruction of the Tympanic Membrane Applying Cartilage: Indications, Techniques and Results. $H N O, 53,573-584$. https://doi.org/10.1007/s00106-005-1280-8

[14] Tos, M. (2009) Cartilage Tympanoplasty. Thieme, Stuttgart, New York, In Print.

[15] Tos, M. (2008) Cartilage Tympanoplasty Methods: Proposal of a Classification. Journal of Otolaryngology-Head \& Neck Surgery, 139, 747-758.

https://doi.org/10.1016/j.otohns.2008.09.021 